\title{
AVALIAÇÃO DAS AULAS SÍNCRONAS POR ESTUDANTES DE ENSINO SUPERIOR
}

Luiz Henrique Dias Correa - luizcorrea@acad.ftec.com.br

Centro Universitário uniftec

Rua Gustavo Ramos Sehbe, 107. Bairro Cinquentenário

CEP 95012-669 Caxias do Sul - RS

Carla Eliana Todero Ritter-cetodero@gmail.com

Centro Universitário uniftec

Rua Gustavo Ramos Sehbe, 107. Bairro Cinquentenário

CEP 95012-669 Caxias do Sul - RS

Neiva Larisane Kuyven-neivakuyven@acad.ftec.com.br

Centro Universitário uniftec

Rua Gustavo Ramos Sehbe, 107. Bairro Cinquentenário

CEP 95012-669 Caxias do Sul-RS

Resumo: A mudança abrupta na condução e organização das aulas no primeiro semestre do ano de 2020 exigiu flexibilidade e tomada de decisões rápidas por parte dos gestores da educação de muitas IES de diferentes países. A pandemia do Coronavírus exigiu que o formato tradicional de aulas presenciais e de configuração definida fosse alterado a fim de dar condições à continuidade e à qualidade das aulas. Alunos e professores tiveram suas habilidade e competências testadas a fim de adaptar-se ao novo modelo e dessa foram encurtar distâncias na construção do conhecimento e articulação dos saberes por meio de aulas síncronas. A avaliação dessa nova maneira de condução das aulas foi realizada por 1210 alunos de uma instituição de ensino superior que responderam a perguntas aberta e fechadas em uma pesquisa quali-quantitativa. Os estudantes, aproximadamente $30 \%$ destes cursando Engenharia, validaram o modelo. Em relação ao recebimento de informações e orientações sobre como seriam os encaminhamentos para as aulas, $95 \%$ as receberam previamente e em tempo hábil. Aproximadamente $94 \%$ dos alunos avaliaram que essas informações satisfaziam as necessidades do momento e aproximadamente $89 \%$ avaliaram que os canais de comunicação foram adequados à necessidade. Durante o período, $82 \%$ dos estudantes estabeleceram uma rotina de estudos, o que facilitou a aprendizagem. Sobre as palavras que resumiriam o aprendizado deste período, os alunos destacaram resiliência, aprender, tecnologia, superação e praticidade como representantes. A dificuldade de acesso, velocidade de conexão e demora entre as perguntas e resposta às dúvidas foram alguns dos aspectos negativos citados pelos alunos.

Palavras-chave: Aulas síncronas. Aprendizagem. Avaliação. 


\section{INTRODUÇÃO}

A organização da mediação pedagógica nos processos de ensino e aprendizagem tiveram rumos alterados no semestre letivo 2020/1 para inúmeras instituições de ensino superior (IES) que recorreram às tecnologias digitais e de comunicação para a manutenção das aulas em função da pandemia do Coronavírus. Reduzir a distância física por meio da comunicação efetiva, exigiu estrutura, diálogo e autonomia na busca da melhor maneira de continuarmos a construção do conhecimento e articulação dos saberes.

Dotta (2014) reforça que na modalidade de educação a distância, emerge a problemática teórica e prática da ação interativa entre professor-aluno e aluno-aluno em atividades síncronas (p. ex., webconferências, videoconferências, lives e chats) e assíncronas (p. ex., fórum, correio eletrônico) realizadas em ambientes virtuais de aprendizagem. Segundo a autora, os protagonistas da comunicação precisam lançar mão de estratégias para realizar a interação verbal e superar as coerções de ordem técnica, espaço-temporal e afetiva, o que os leva a produzir, na prática do diálogo virtual, novas formas enunciativas. Por permitir interação em tempo real, conjugando áudio, imagem e movimento, a webconferência (live) é uma das mídias que mais consegue se aproximar da interação presencial.

A concretização da aula virtual síncrona por webconferência é uma atividade complexa que confere os diferentes papeis do professor: gestor, pedagógico, técnico e mediador. Marchioni et al (2018) em trabalho organizado por Dotta (20018) destacam as funcionalidades que tornam o papel do professor tão múltiplo na aula síncrona, tendo de dar conta de todas elas, além do conteúdo e interação dos envolvidos na aula. A presença síncrona, bem como os papeis docentes bem desempenhados são responsáveis por uma sensação de pertencimento, capaz de promover maior engajamento do aluno. E é essa a pergunta que toma conta dos professores e gestores de IES: Como manter o grupo de alunos e professores engajado nesse novo processo?

\section{REFERENCIAL TEÓRICO}

Para Dotta (2009), a presença síncrona de professores e alunos favorece a sensação de pertencimento ao grupo, promovendo esse engajamento. A promoção da aprendizagem significativa, colaborativa ou por pesquisa defendida por Demo (1996) é uma das formas de manter o aluno centrado no aprender e seu engajamento será proporcional ao sentimento de pertencimento.

A imprevisibilidade na prática em aulas síncronas é tão diversa quanto o número de ações, construções, consequências e resultados entre os elementos participantes: humanos, técnicos e sistemas. O domínio da tecnologia é essencial no planejamento e execução das aulas.

Dotta e Jorge (2014) em trabalho de Dotta (2018) avaliam que as aulas síncronas necessitam de planejamento tanto burocrático como pedagógico. A necessidade de uma equipe multidisciplinar, o desenvolvimento de mídias digitais e uso de ferramentas de comunicação são elementos que podem assegurar a qualidade da aula.

Nesse sentido, Diaz et al (2014) destacam que o planejamento do ensino, caracterizado pelo conhecimento prévio e pelas características dos alunos e professores permitem o desenvolvimento de habilidades no ambiente síncrono de aprendizagem. Também reforçam que os recursos interativos, as reações pessoais dos professores, as interações dos alunos e a relação 
com o conteúdo são indicativos de possibilidades viáveis e de sucesso no ambiente virtual. Para os autores, são importantes os momentos de treinamento e capacitação para o uso de ferramentas para as aulas síncronas a fim de conferir segurança e autonomia para os estudantes.

No que tange a autonomia do estudante em ambientes de aprendizagem EaD, Arcúrio (2008) defende que a separação geográfica com o professor não deve ser um impeditivo para o não comprometimento com as suas responsabilidades e na participação ativa, visto que a tecnologia seria uma aliada considerando a flexibilização de horários, atendimentos e formas de avaliação. Nesse sentido, o autor defende:

\begin{abstract}
A autonomia na aprendizagem é algo peculiarmente democrático e requer disciplina, decisão, organização, persistência, motivação, avaliação e responsabilidade. No que tange à educação a distância, ser um aprendiz autônomo é saber utilizar-se dos recursos tecnológicos que esta modalidade disponibiliza, adequando-os às reais necessidades individuais, o que significa dizer: flexibilidade de horário para o estudo, atendimento personalizado, inovação das metodologias de ensino, aperfeiçoamento e novas possibilidades de avaliação da aprendizagem, sem denegrir suas normatizações legais, assim como a ampliação de relacionamentos interpessoais.
\end{abstract}

Para manter o engajamento e a autonomia em ambiente virtual é necessário, segundo Scherer (2005), que o professor articule e incentive os espaços de interação e aprendizado dos estudantes. Segundo o autor, o ambiente deve ser de convivência, de parceira e de ação comunicativa. Participar sem interagir com os demais alunos implica em ser apenas transeuntes ou zapeadores dos ambientes virtuais de aprendizagem.

Assim, avaliar a percepção do aluno perante às aulas síncronas por meio virtual foi o objetivo deste trabalho.

\title{
3 PROCEDIMENTO METODOLÓGICO
}

A avaliação foi desenvolvida nos cursos de Bacharelado do Grupo UNIFTEC, com unidades situadas em Caxias do Sul, Bento Gonçalves, Novo Hamburgo e Porto Alegre e teve por objetivo analisar e apresentar a percepção dos alunos a respeito do modelo de aulas síncronas no qual os professores destas unidades desenvolveram no período de restrições das aulas devido a pandemia do Coronavírus. Neste semestre de 2020/01 houve somente uma semana de aulas presencias, sendo na segunda semana de aula houve capacitações docentes a fim de que na terceira semana de aula iniciava-se um novo ciclo, aulas online para todos os alunos.

Para avaliarmos a aceitação da comunidade discente e buscar melhorias nas atividades desenvolvidas nas atividades síncronas foi realizada a pesquisa qualitativa e quantitativa. McDaniel e Gates (2003) reforçam que a pesquisa qualitativa pode ser utilizada para analisar as atitudes, os sentimentos e as motivações, sendo normalmente caracterizada por amostras pequenas e tendo desempenho superior na detecção de problemas que podem passar despercebidos. Para Yin (2008), o estudo de caso é uma investigação empírica que investiga um fenômeno contemporâneo em seu contexto real, especialmente quando os limites entre o fenômeno e o contexto não estão claramente definidos. 
A pesquisa foi realizada a partir de um questionário com perguntas abertas e fechadas para 6000 alunos que cursavam o semestre letivo, sendo que 1210 retornaram com as respostas, sendo $36 \%$ estudantes de Engenharia. As perguntas fechadas tinham a possibilidade de inserção de comentários.

O formulário de questões foi enviado após 60 dias do início das aulas síncronas por meio online inserida no Ambiente Virtual de Aprendizagem e teve a sua realização disponível por uma semana. Os estudantes não se identificaram para a realização do mesmo.

\section{RESULTADOS E DISCUSSÃO}

A mudança abrupta na condução e organização das aulas no primeiro semestre do ano de 2020 exigiu flexibilidade e tomada de decisões rápidas por parte dos gestores da educação de muitas IES de diferentes países. A pandemia do Coronavírus exigiu que o formato tradicional de aulas presenciais e de configuração definida fosse alterado a fim de dar condições à continuidade e à qualidade das aulas. Alunos e professores tiveram suas habilidade e competências testadas a fim de adaptar-se ao novo modelo.

Dessa forma, avaliar quais os impactos gerados, permite identificar falhas, mas principalmente entender como o processo de aprender pode se reinventar.

A primeira ação foi mobilizar o grupo de mais de 6000 alunos para que todos tivessem acesso às informações de modo rápido e eficaz. Identificou-se que $95 \%$ dos alunos que responderam ao questionário receberam previamente e em tempo hábil as informações e orientações sobre como seriam os encaminhamentos para as aulas. Aproximadamente $94 \%$ dos alunos avaliaram que essas informações satisfaziam as necessidades do momento e aproximadamente $89 \%$ avaliaram que os canais de comunicação foram adequados à necessidade.

Desenvolver habilidades complexas envolve a capacidade de organização e sistematização. Assim, foi questionado se os estudantes conseguiram estabelecer uma rotina de estudos durante o período de aulas síncronas e online e $82 \%$ das respostas foi afirmativa. Dos $18 \%$ que não estabeleceram rotina de estudo, os argumentos foram:

\footnotetext{
"Não tenho um ambiente adequado para estudo, não consigo estabelecer um horário fixo para estudar sem interrupções, e o horário que ocorrem as aulas é o horário que mais tem interrupções em minha casa. Como continuei trabalhando normalmente, demorei bastante tempo para me adaptar a este método, pois nunca tinha realizado uma aula online. Estou conseguindo estabelecer uma rotina de estudos agora, passados meio semestre, mas ainda não estou $100 \%$ organizada.

Eu preciso cuidar dos meus sobrinhos quando eu estou em casa, e fica ruim para eu me concentrar."
}

Lopes et al (2019) em pesquisa sobre a rotina de estudos afirmaram em relação ao comportamento de estudar que 70,5\% dos estudantes não possuem uma rotina de estudos, com dias e/ou horários fixos para se dedicar a essa atividade. Segundo os autores e em referência a Cortez et al (2010), isso indica que não ter condições favoráveis para o estudar tornar-se um operante discriminado, pois a falta de rotina não contribui para que um momento ou um local específico torne-se um estímulo discriminativo que aumente a probabilidade da ação de estudar ocorrer no futuro.

A percepção em relação ao desenvolvimento de habilidades e competências durante o período de aulas online e síncronas, os alunos responderam à pergunta: Pensando em sua 
aprendizagem, em termos de conteúdo, habilidades e competências, o que você percebeu? Aproximadamente $35 \%$ dos alunos responderam que aumentou, $28 \%$ que diminuiu e o $37 \%$ permaneceu igual ao período anterior.

No ensino híbrido espera-se que os alunos estejam mais engajados em seu processo de aprendizagem, entendido como processo que se baseia no desenvolvimento de competências, autonomia e domínio gradativo dos conhecimentos e construção de relacionamentos produtivos. Essa caraterística do ensino híbrido apoia o desenvolvimento do quarto pilar da educação, o Aprender a Ser, que visa a transformação do ser humano e o desenvolvimento do corpo e da alma (Passos, 2018).

Almeida (2010) defende que, em aula síncronas, a autonomia reflete o grau de controle que o aluno tem sobre os processos de ensino e aprendizagem. Um aluno autônomo ideal é uma pessoa emocionalmente independente de um professor. Para o autor, é o aluno, e não o professor, quem tem a prioridade na determinação dos objetivos, das experiências de aprendizagem e das decisões decorrentes do processo de avaliação

Ao serem questionados sobre o interesse pelo curso e pelo estudo, aproximadamente $54 \%$ dos alunos responderam que permaneceu o mesmo, $30 \%$ aumentou e $16 \%$ diminuiu. O fato de ter aumentado ou diminuído teve a influência de diferentes fatores (Figura 1).

Figura 1 - Fatores que influenciaram o aumento ou diminuição do interesse pelo curso durante as aulas online.

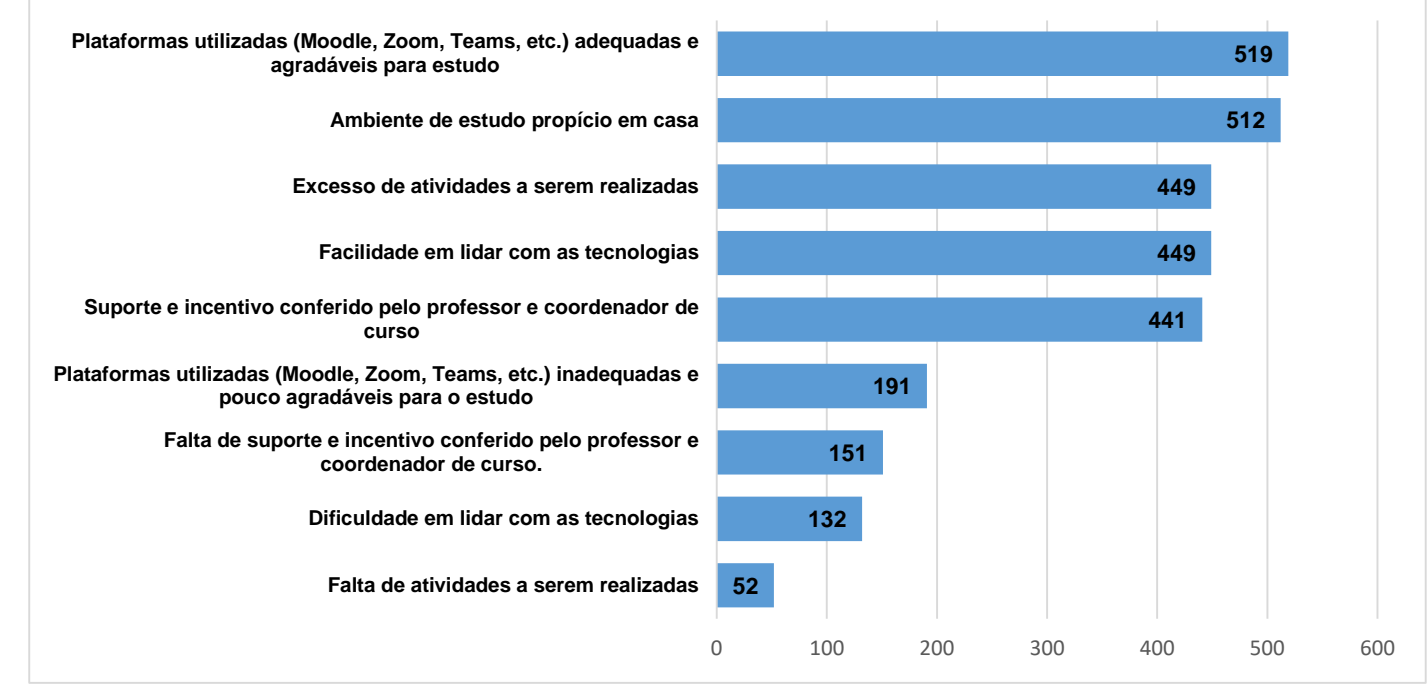

Fonte: Autores

Passos (2018) afirma que o reconhecimento dos benefícios do modelo pedagógico do ensino híbrido, tais como flexibilidade, facilidade de acesso e integração de tecnologias e multimídia sofisticadas vem crescendo nas instituições de ensino superior e sua implementação é considerada uma das políticas de inclusão que pode intervir na contenção dos índices de evasão, retenção e reprovação.

Conforme a Figura 1 observa-se a falta de atividades a ser desenvolvida pelos professores explicada também pela dificuldade em lidar com as novas tecnologias. Sugere-se a realização de capacitações e treinamentos para os professores e alunos a fim de que possam apresentar autonomia no ambiente virtual de aprendizagem. 
Quando questionados pela pergunta: Levando em consideração todas as disciplinas nas quais você teve aulas online neste período, como você avalia os ferramentais digitais que foram utilizadas pela instituição? Dos 1210 alunos que responderam, 84\% consideraram satisfatórios. Dos que não o consideraram satisfatório, os comentários envolviam aspectos domésticos e técnicos e afirmaram que:

Pelo fato da instabilidade da conexão, tanto por parte dos professores quanto por parte dos alunos, onde por diversas vezes as aulas ficam travadas por este motivo. Muito tempo perdido, pois, na maioria das vezes o raciocínio era interrompido pois excedia o tempo de chamada do zoom. Outro ponto são os colegas falando com o microfone ligado, interrompendo o professor.

Além de avaliar as ferramentas digitais, os alunos foram instigados a escreverem uma palavra que descrevesse o que mais o impactou positiva e negativamente nessa experiência de aulas síncronas e online. A partir das respostas dos alunos, construiu-se uma nuvem de palavras, as palavras maiores representam as de maior frequência nas respostas dos alunos (Figura 2).

Figura 2- Representação das frequências das palavras que representam o impacto positivo da experiência em aulas síncronas e online

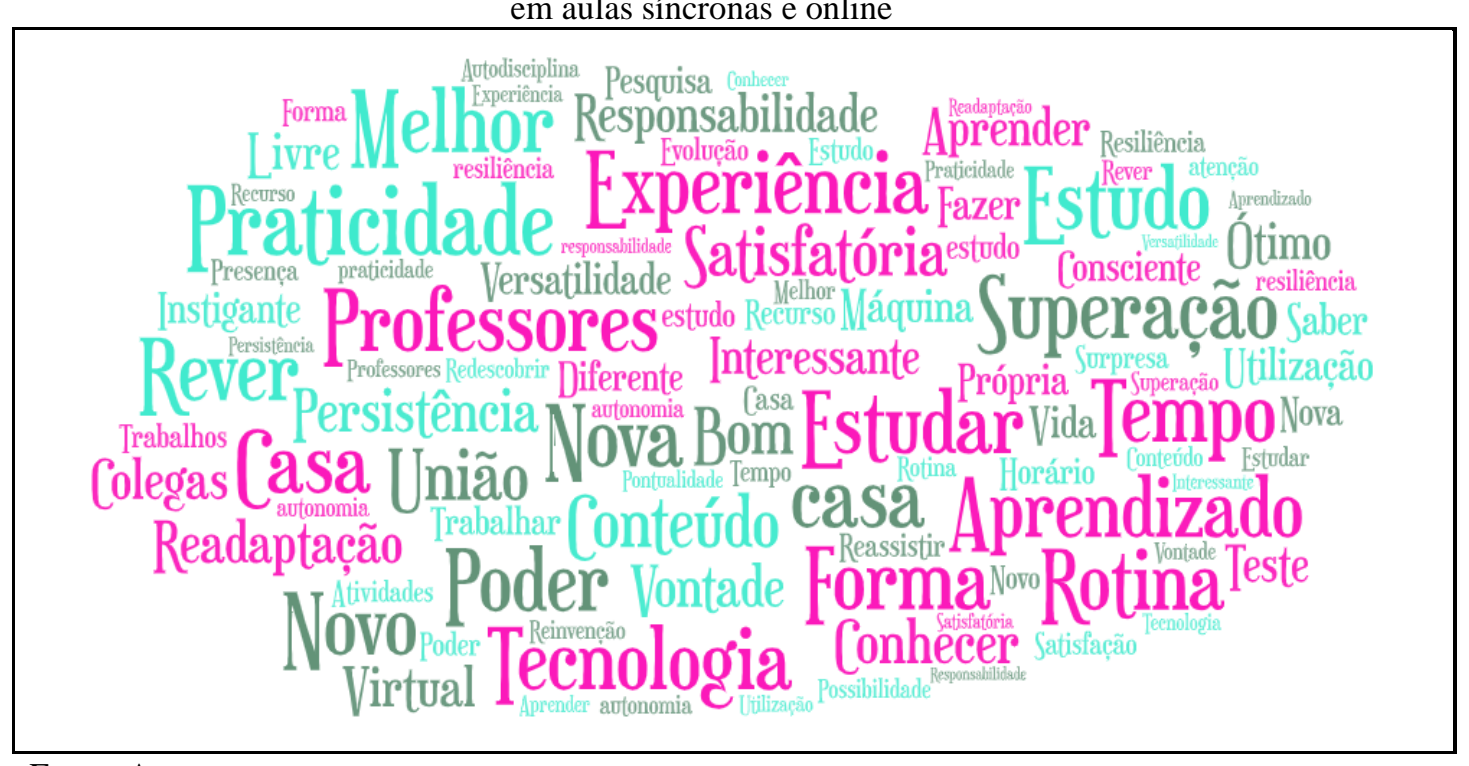

Fonte: Autores

Como relato dessas experiências positivas, pode-se destacar pelos relatos dos alunos:

As aulas estão muito mais organizadas e didáticas, métodos de avaliação estão mais coerentes com aulas!

Tirou meu pré-conceito em relação as aulas EAD não funcionarem direito, e toda uma nova descoberta de se trabalhar com os estudos, e adaptando junto aos professores.

Tenho mais vontade de estudar, pois o tempo que perdia em deslocamento me deixava desmotivada.

Ter autodisciplina em qualquer atividade ou compromisso que eu tiver, tenho que fazer independente se eu tenho vontade ou não, mas é um compromisso comigo que eu tenho todos os dias.

O esforço, numa aula online requer muito mais atenção, esforço, e muita dedicação e leituras principalmente!! Isso mostra que somos capazes de muito cada dia mais. 
Batista Júnior (2018) destaca que necessidades que as IES precisam ficar atentas sobre as modalidades de ensino e o ensino híbrido: o contexto educativo mudou; que novas exigências surgem diante dessa realidade; que a instituição de ensino deixou de ser a única fonte de conhecimento; e que a aprendizagem ocorre de forma colaborativa, onde todos contribuem na construção do conhecimento, criando uma cultura de aprendizagem coletiva e ao mesmo tempo, autônoma.

Em relação aos aspectos negativos citados pelos alunos durante as aulas online e síncronas a maioria refere-se basicamente ao tipo de plataforma utilizada pelo professor e à conexão de internet. Segundo Stewartn et al. (2011) a mudança da modalidade presencial para o online pode ser impactante para os estudantes, que podem percebê-lo como negativo na sua aprendizagem, reportando a diferença entre ritmos do ensinar do professor.

Também houve relatos sobre a falta das relações pessoais:

Falta de me sentir instigado a estudar mais, sem senso de competitividade algum.

Em consideração a pandemia, o contato direto com os docentes da modalidade presencial fica obviamente prejudicado.

O negativo foi não ter o contato devido com grupos e professores para sanar certas dúvidas.

Alguns alunos também afirmaram a necessidade de respostas mais rápidas em relação às dúvidas sobre as aulas. Para essa situação, muitos professores utilizaram o Whatsapp, um aplicativo de comunicação utilizado por muitas pessoas no dia-a-dia, e que para a EaD aponta como um recurso para realização de encontros síncronos e assíncronos como o chat e o fórum, por exemplo. Blauth et al (2019) estudaram as facilidades do uso do WhatsApp para a construção de textos e realização de fóruns, validando a ferramenta de modo síncrono e assíncrono.

\section{CONSIDERAÇÕES FINAIS}

A partir das considerações, observou-se que os estudantes se adaptaram ao novo formato de ensino, com aulas síncronas. Alguns pontos foram considerados como positivos, como por exemplo, a disponibilidade de ferramentas, de gravação das aulas, ficando disponíveis para assistirem posteriormente e a vantagem de estarem em local seguro durante o período de redação deste trabalho. Como aspectos negativos, os estudantes destacaram o excesso de atividades, visto que muitos alunos continuaram suas atividades profissionais, sem interrupções.

As aulas síncronas demonstraram-se ser uma possibilidade, mas há a necessidade de conhecimento em relação às peculiaridades dos cursos, visto que há dinâmicas específicas que demandam adaptações, garantindo a qualidade das aulas.

\section{REFERÊNCIAS}

ALMEIDA, Luis Rogério Gomes de. Ensino colaborativo de eletrônica em ambiente síncrono e assíncrono usando software livre. Dissertação de Mestrado. Campinas, 2010. ARCÚRIO, Mateus. Educação. Autonomia do aprendiz na educação a distância. PARTES A SUA REVISTA DIGITAL. Dez.2008.

BRASIL. Conselho Nacional de Educação. Câmara de Educação Superior - CNS/CES. Resolução $\mathrm{n}^{\circ}$ 11, de 11 de março de 2002. Institui Diretrizes Curriculares Nacionais do Curso 
de Graduação em Engenharia. Diário Oficial da República Federativa do Brasil, Brasília, DF, 2002.

BATISTA JÚNIOR, Roberto Oliveira. Ensino híbrido: um estudo sobre a inserção de até 20\% de EAD na carga horária de cursos presenciais da UFPE. Dissertação de Mestrado da Universidade Federal de Pernambuco, 2018.

DEMO, Pedro. Educar pela Pesquisa. Campinas, Autores Associados. 1996.

DÍAZ, Laura Alonso; Esteban, Prudencia ; Yuste Tosina, Rocío; Masa, Juan Arias . Usos de aulas virtuales síncronas en educación superior usage of synchronous virtual classrooms in higher education. Píxel-Bit. Revista de Medios y Educación. № 45. Julio 2014. ISSN: 11338482. E-ISSN: 2171-7966. doi: http://dx.doi.org/10.12795/pixelbit.2014.i45.14

DOTTA, Sílvia. (Organizadora). Aulas virtuais síncronas: Condução de webconferência multimodal e multimídia em Educação a Distância Santo André, Editora da UFABC, Coleção Intera, 2014.

DOTTA, S. Aprendizagem dialógica em serviços de tutoria pela internet: Estudo de caso de uma tutora em formação em uma disciplina a distância. São Paulo, Universidade de São Paulo, Faculdade de Educação, Tese de doutorado.2009.

LOPES, Carlos Eduardo.; Laurenti, Carolina.; Martins, Felipe Boldo.; Carrille, Rachel Patrão.; Esquilage, Camila Rocca.; Souza, Guilherme Augusto Ascenscio Rosa de.; Macerau, Walkíria Maria de Oliveira. Uma investigação das práticas de estudo de graduandos de ciências humanas. ACTA COMPORTAMENTALIA Vol. 27, Núm. 2 pp. 179-196, 2019.

PASSOS, Marize Lyra Silva. MM-Híbrido - Modelo De Maturidade Para Avaliação Do Ensino Híbrido Em Instituições De Ensino Superior. Tese de doutorado pela Universidade Federal do Rio Grande do Sul, 2018.

SCHERER, Sandra. Uma estética possível para a educação bimodal: aprendizagem e comunicação em ambientes presenciais e virtuais. Uma experiência em estatística aplicada à educação. São Paulo: PUC, 2005. 240 p. Tese (Doutorado) - Programa de Pós-graduação em Educação: Currículo, Pontifícia Universidade Católica de São Paulo, São Paulo, 2005.

STEWART, A. R.; HARLOW, D. B.; DEBACCO, K. Students' experience of synchronous learning in distributed environments. Distance Education, 32, p. 357-381. 2011. 


\title{
EVALUATION OF SYNCHRONIC CLASSES BY HIGHER EDUCATION STUDENTS
}

\begin{abstract}
The abrupt change in the conduct and organization of classes in the first semester of 2020 required flexibility and quick decision-making by education managers from many HEIs in different countries. The Coronavirus pandemic required that the traditional format of faceto-face classes and a defined configuration be changed in order to provide conditions for the continuity and quality of classes. Students and teachers had their skills and competences tested in order to adapt to the new model and this was to shorten distances in the construction of knowledge and articulation of knowledge through synchronous classes. The evaluation of this new way of conducting classes was carried out by 1210 students from a higher education institution who answered open and closed questions in a quali-quantitative survey. The students, 36\% of them studying Engineering, validated the model. Regarding the receipt of information and guidance on how referrals to classes would be made, 95\% received them in advance and in a timely manner. Approximately $94 \%$ of the students assessed that this information met the needs of the moment and approximately $89 \%$ assessed that the communication channels were adequate to the need. During the period, $82 \%$ of students established a study routine, which facilitated learning. Regarding the words that would summarize the learning of this period, the students highlighted resilience, learning, technology, overcoming and practicality as representatives. The difficulty of access, connection speed and delay between questions and answers to doubts were some of the negative aspects mentioned by the students.
\end{abstract}

Keywords: Synchronous classes. Learning. Evaluation. 